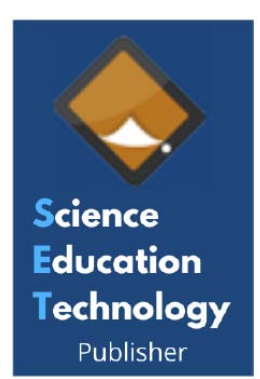

\title{
Impact of Chromium Addition on the UTS and ETF of Aluminium Alloy AA6061 Chips Based Composite
}

\author{
Chan Boon Loong ${ }^{*}$, Mohd Amri Lajis, Shazarel Shamsudin and Nur Elisa Zainodin \\ Sustainable Manufacturing and Recycling Technology, Advanced Manufacturing and Materials Centre (SMART- \\ AMMC), Universiti Tun Hussein Onn Malaysia (UTHM), 86400 Parit Raja, Batu Pahat, Johor, Malaysia
}

\section{Article Info:}

Keywords:

Aluminium matrix composite,

Chromium,

Solid-state recycling,

Hot press forging.

Timeline:

Received: December 29, 2021

Accepted: January 15, 2022

Published: February 04, 2022

Citation: Chan BL, Lajis MA, Shamsudin $S$, Zainodin NE. Impact of Chromium Addition on the UTS and ETF of

Aluminium Alloy AA6061 Chips Based Composite. J Basic Appl Sci 2021; 18 : 26-32.

DOI: https://doi.org/10.29169/1927-5129.2022.18.04

\begin{abstract}
:
Aluminium matrix composite has been increasingly developed due to the impressive performances demonstrated, mechanically and physically. The related properties were enhanced with the addition of reinforcing materials and this tailormade composite can be used in the area of automotive, aerospace and military. In this study, the matrix composite was developed directly from aluminium chips without remelting through a series of hot press forging operations. This process involved heating the aluminium chip mixtures with 1 to $8 \mathrm{wt} \%$ chromium content above the recrystallization temperature. Then, the uniaxial force was subsequently applied onto the composite. For performance measures, the hot pressed composites were tested for the ultimate tensile strength (UTS) and elongation to failure (ETF). The composite with $2 \mathrm{wt} \%$ of chromium exhibits significant improvement compared to other samples, with the UTS and ETF reached to $215.37 \mathrm{MPa}$ and $30.65 \%$ respectively. This sample exceeds the minimum stress and strain of stock aluminium AA6061-T4. Furthermore, the addition of chromium beyond $2 \mathrm{wt} \%$ would generally cause reduction of the mechanical properties of the composite.
\end{abstract}

${ }^{*}$ Corresponding Author

E-mail: chan.boon.loong@gmail.com

(C) 2022 Chan et al.; Licensee SET Publisher.

This is an open access article licensed under the terms of the Creative Commons Attribution License (http://creativecommons.org/licenses/by/4.0/) which permits unrestricted use, distribution and reproduction in any medium, provided the work is properly cited. 


\section{INTRODUCTION}

Over the last decade, composite materials have been the leading material of choice in the modern technological era. This is apparently due to the performance enhancement of the aluminium matrix material with reinforcing materials. The aluminium matrix composite demonstrates excellent physical and mechanical properties, at the same time having a low density, high toughness, and corrosion resistance [1]. The comprehensive improvements led to the utilization of aluminium matrix composites in automotive, electronics, aerospace, and military industries [2,3]. However, the aluminium matrix composite's high production cost becomes the downside of this material, where the primary usage is confined to military applications [4].

Aluminium chips can be potentially used as the matrix in the aluminium matrix composite, which further reduces the overall process's production cost. Furthermore, it provides an alternative way to direct recycling of aluminium scraps [5,6]. Past studies on the solid-state recycling of aluminium chips using the hotpressed forging technique showed favorable physical and mechanical properties [7]. The chips were heated above the recrystallization temperature for consolidation, which gradually developed a strong bonding due to uniformly fine oxide particle dispersions [8]. Besides, a sufficient soaking time must be allowed to completely re-dissolve the second phase [9].

Previous studies show that the amount of reinforced materials plays a vital role in the composite's resulting physical and mechanical properties [10]. Lajis et al. [11] concluded that the ultimate tensile strength (UTS) and elongation to failure (ETF) of hot-pressed composite increase as the amount of alumina increases to $2 \mathrm{wt} \%$. On top of that, several researchers also found similar trends, where the UTS and ETF increased as the alumina content increases up to $10 \mathrm{wt} \%$ in composite produced by the powder metallurgy $[12,13]$.

This work focuses on the effect of chromium addition in the aluminium alloys AA6061 chips based matrix composite. Hot forging was used as the primary process to produce the aluminium matrix composite. Significant reduction of porosity has been observed on the developed composite. The performances were analyzed merely on the UTS and ETF of the composite. The results obtained were compared with the standard's theoretical data, and the expected properties were supposed to be closed to an existing monolithic stock aluminium alloy.

\section{MATERIALS AND METHODS}

Chromium powder (99\% purity, Dongguan Zhiding Electronics Technology Co. Ltd, China) with the particle size ranging from $70-80 \mathrm{~nm}$ and the as-cast aluminium alloy AA6061 (99\% purity) were used as reinforced and matrix materials, respectively. The amounts of chromium powder were varied to 1, 2, 4, 6, and 8 wt\%. The as-cast aluminium AA6061 was examined to confirm the standard specified for aluminium and aluminium-alloy sheet and plate [14]. The minimum UTS of alloy 6061- T4 is $205 \mathrm{MPa}$ with a minimum ETF of $18 \%$.

The chips were derived through the high-speed milling process by the Sodick-MC430L machine. The machining parameters selected are shown in Table 1. The resulting chips were then cleaned with acetone $(\mathrm{C} 3 \mathrm{H} 6 \mathrm{O})$ in an ultrasonic bath for 30 minutes [15]. Figure 1 shows the dried chips after taken out from the drying oven set at $60^{\circ} \mathrm{C}$ for 30 minutes.

Table 1: Milling Parameters Selected [16]

\begin{tabular}{|c|c|}
\hline Parameter & Value \\
\hline \hline Cutting S peed, $V(\mathrm{~m} / \mathrm{min})$ & 110 \\
\hline Feed, $f(\mathrm{~mm} /$ tooth $)$ & 0.05 \\
\hline Depth of cut, doc $(\mathrm{mm})$ & 1.0 \\
\hline
\end{tabular}

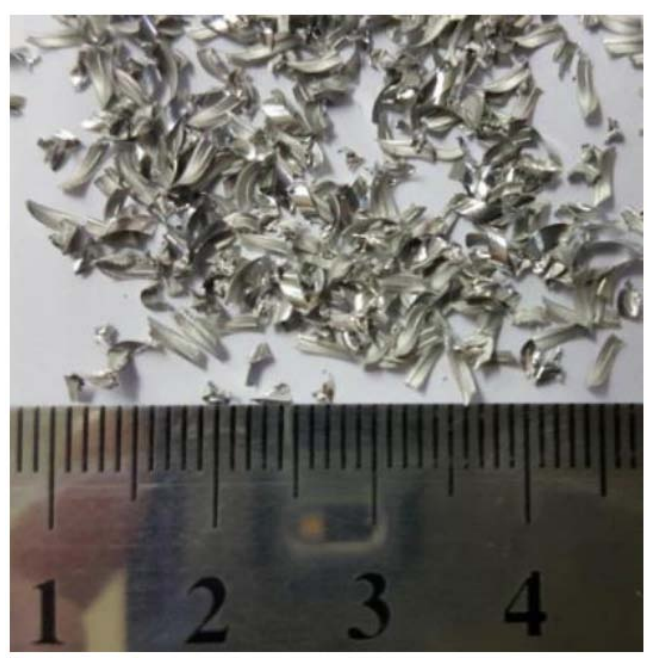

Figure 1: Aluminium chips.

The cleaned aluminium chips were then mixed with the chromium powder following the reinforcing content of 1 , $2,4,6$, and $8 \mathrm{wt} \%$, while the remaining constituent was the aluminium chips as the matrix. The mixing process takes 1 hour at $50 \mathrm{rpm}$ in the three-dimensional mixer (planetary movement). The mixture of aluminium chips 
and chromium were then poured into the mould and heated up in the hot forging machine. When the furnace's temperature reaches $530^{\circ} \mathrm{C}$, the temperature was maintained for 1 hour. This is required to homogenize the temperature throughout the mould and the mixture inside. Then a 35 tonnes uniaxial force was applied perpendicularly onto the mixture for 120 minutes [17]. The hot-pressed composite was then removed and quenched directly in the water bath at $60^{\circ} \mathrm{C}$ for 5 seconds, which can be denoted as T1temper. This newly developed composite is supposed to be comparable theoretically with the stock aluminium alloy AA6061-T4. This is because both materials experienced a similar solution heat treatment and natural aging until the stable condition $[18,19]$. The graphical representation of the hot press forging and heat treatment progression is depicted in Figure 2.
The dimensions of the mould for the hot press forging followed ASTM-E8, common standards for specimen preparation in tensile test [20] as shown in Figure 3. The samples produced were subsequently pulled to fail to determine the mechanical properties of UTS and ETF. The Universal Testing machine was used to carry out all tensile tests throughout the study with a constant $1.00 \mathrm{~mm} / \mathrm{min}$ speed.

\section{RESULTS AND DISCUSSION}

The addition of 2 wt \% of $\mathrm{Cr}$ results in the highest obtainable UTS of $215.37 \mathrm{MPa}$ compared to other developed composites. The UTS of $2 \mathrm{wt} \%$ of $\mathrm{Cr}$ surpasses the minimum UTS of stock aluminium AA6061-T4, as shown in Figure 4. The fundamental behind the improvement is that the matrix aluminium was held firmly by the reinforced particle of $\mathrm{Cr}$ and it is

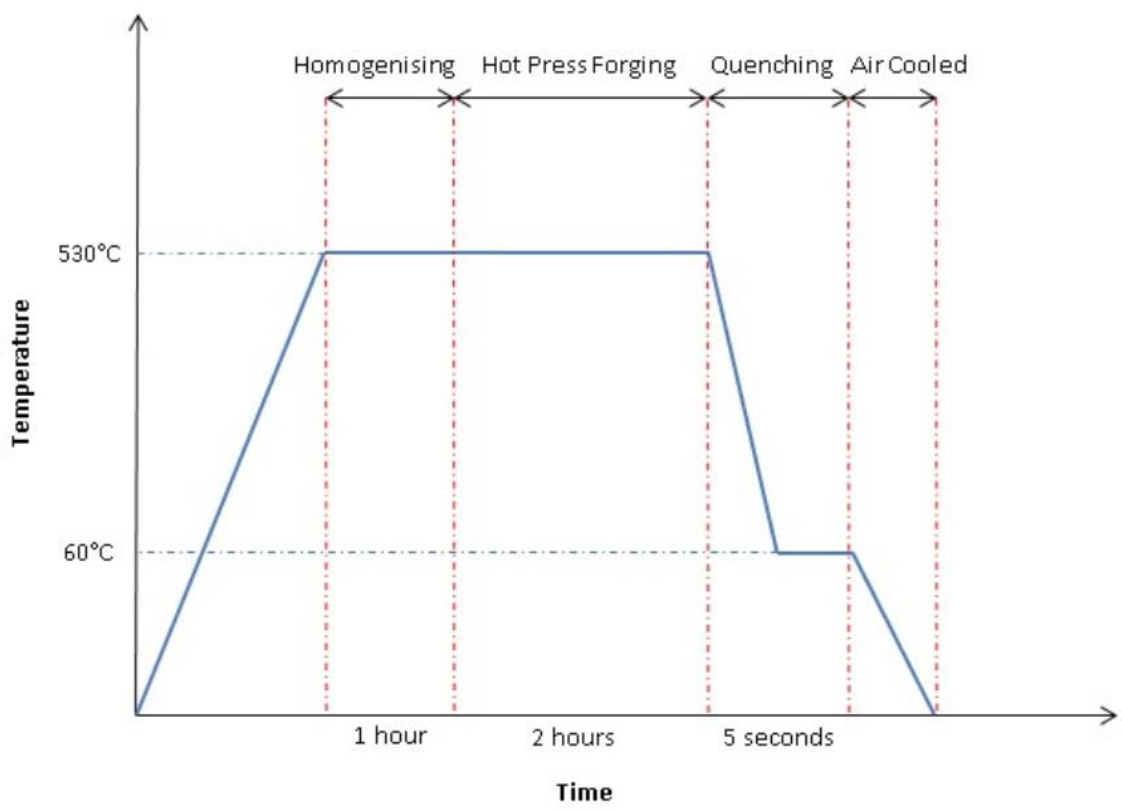

Figure 2: Temperature profile for hot press forging and heat treatment at T4 condition.

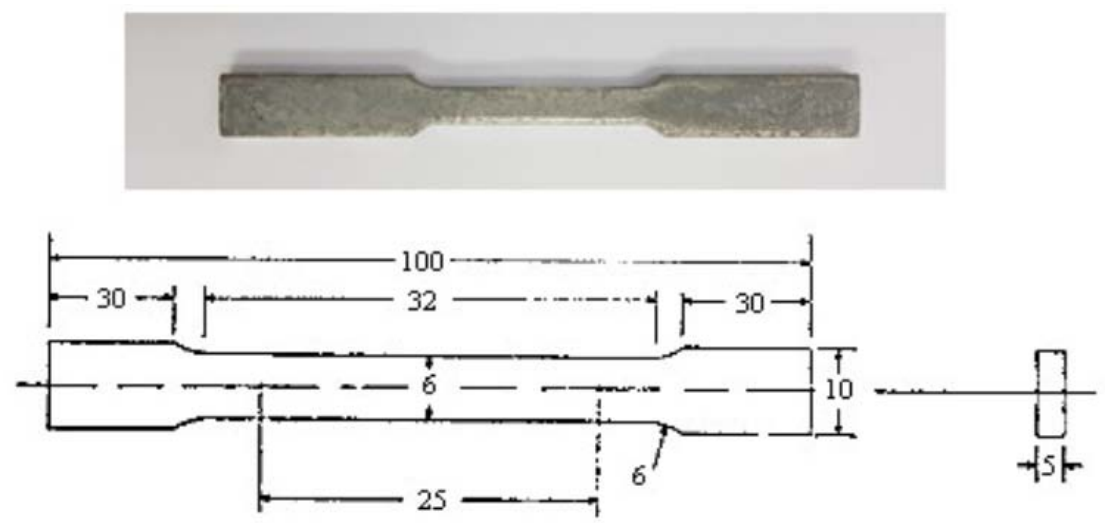

Figure 3: ASTM-E8 standard's specimen (in $\mathrm{mm}$ ). 


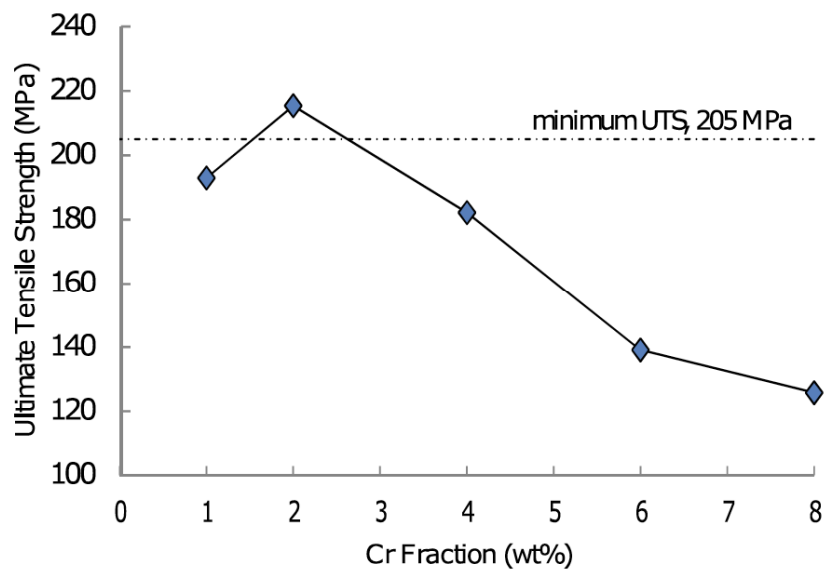

Figure 4: Results of UTS with the increase of chromium content.

further prevents dislocation movement of the aluminium chips through dispersion strengthening mechanism [9,11,21]. The addition of more $\mathrm{Cr}$ constituents in composite leads to the reduction of UTS performance. The reinforced particles are seen to agglomerate by increasing their content in the composite quickly. The mixing process became inefficient and unable to spread out the $\mathrm{Cr}$ powder throughout the mixture homogeneously. Inhomogeneous mixing of the matrix composite with the reinforced material forms a weak interfacial bonding and leads to higher porosity, resulting in a composite with low UTS performance $[12,22]$. The microstructure of the hot-pressed specimen is shown in Figure 5.

The ETF behaviour is shown in Figure 6 exhibits a similar trend as in the UTS of the composite. Initially, the ETF of the composite increases from $24.81 \%$ to $30.65 \%$, with the increase of chromium content from 1 $\%$ to $2 \%$, as shown in Figure 6 . With the presence of appropriate chromium content in the composite, the pores and voids in the aluminium matrix are reduced considerably [23]. On top of that, strong mating surface bonds between chip-to-chip and chip-to-powder regions are primarily obtained from the hot pressing operation. Therefore, the composite's overall porosity is reduced [22].

Further increment of chromium in the composite from $2 \%$ to $4 \%$ decreases the ETF to $24.11 \%$. The ETF

\section{a}

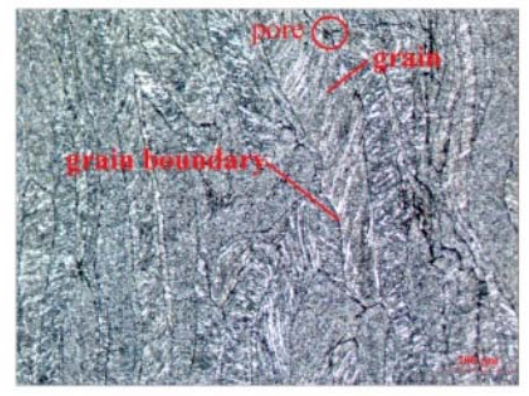

C

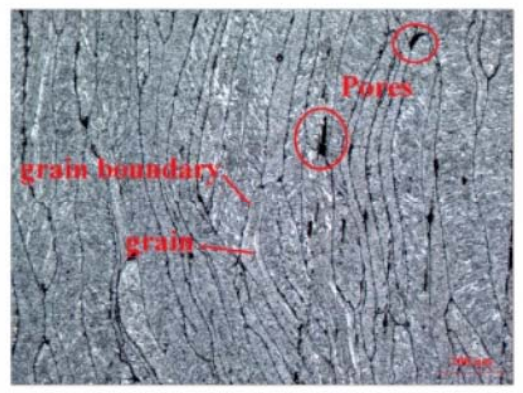

b

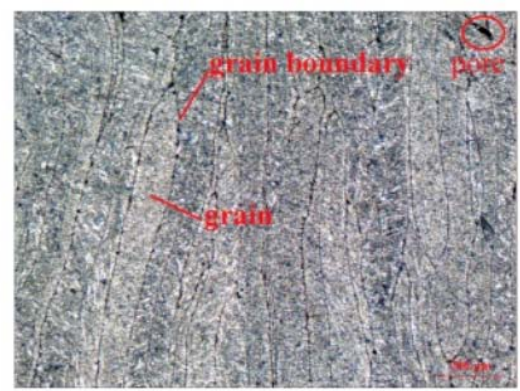

d

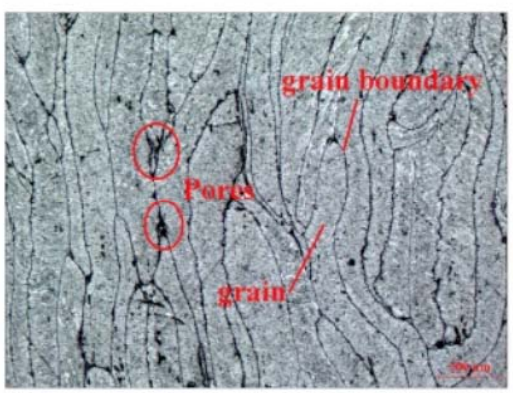

e

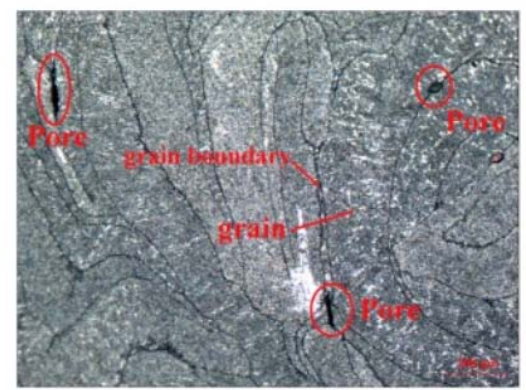

Figure 5: Microstructure of hot pressed aluminium chips with $\mathrm{Cr}$ at a) $1 \%$, b) $2 \%$, c) $4 \%$, d) $6 \%$ and e) $8 \%$. 
continues to decrease to $11.53 \%$ for composite with $6 \%$ chromium. The reduction of ETF starts to reach a plateau at $6 \%$, where the further addition of chromium will not significantly affect the ETF of the composite. This phenomenon occurs as clustering of excess chromium in the composite began to form, when the chromium's addition beyond the optimal of $2 \%$. These clusters cause the weaker region's formation throughout the composite [11], thus reducing the ETF of the composite.

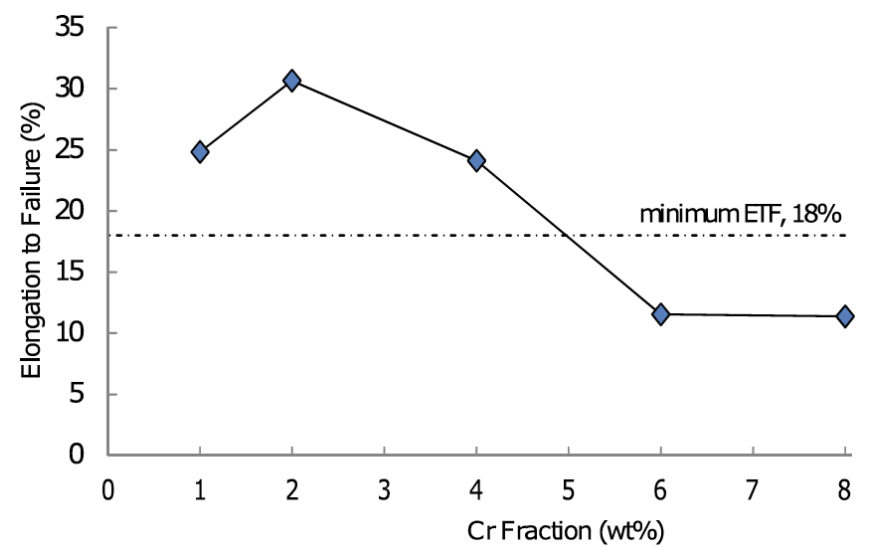

Figure 6: Variations in ETF as a result of chromium content increment.

From Figure 7, the stress-strain behaviour with varying amounts of chromium content exhibits similar trends. The minimum boundary for AA6061-T4 is at $205 \mathrm{MPa}$ for minimum stress and minimum strain at $18 \%$.
Aluminium composite of $2 \%$ chromium surpasses the minimum boundary of the standard AA6061-T4 with true stress barely passing the minimum. While the chromium content of 1,2 , and $4 \%$ greatly surpass the minimum elongation point. There is a significant improvement in the composites' stress-strain behaviour at $2 \%$, which is denoted as the highest and optimal chromium content in this study [24]. However, further addition of chromium leads to the declination for the final stress-strain of the composites. The addition of the chromium beyond the optimal causes the concentration of the reinforcing phase in the composite, thereby enhancing the local stresses from plastic deformation restriction. Furthermore, the reinforcing phase's clustering reduces the inter-particle distance of the voids and crack in the composite, which in turn reduces the overall ductility [25].

\section{CONCLUSION}

- $\quad$ Fabrication of chromium reinforced aluminium chip matrix composite through hot pressed forging has been achieved. The composites exhibit a significant improvement in terms of UTS and ETF. Through this study, the following conclusions have been drawn. The chromium amount strongly influences the mechanical properties of the composite in the composite, where the optimal amount of chromium stands at $2 \mathrm{wt} \%$. Further addition of chromium resulted in

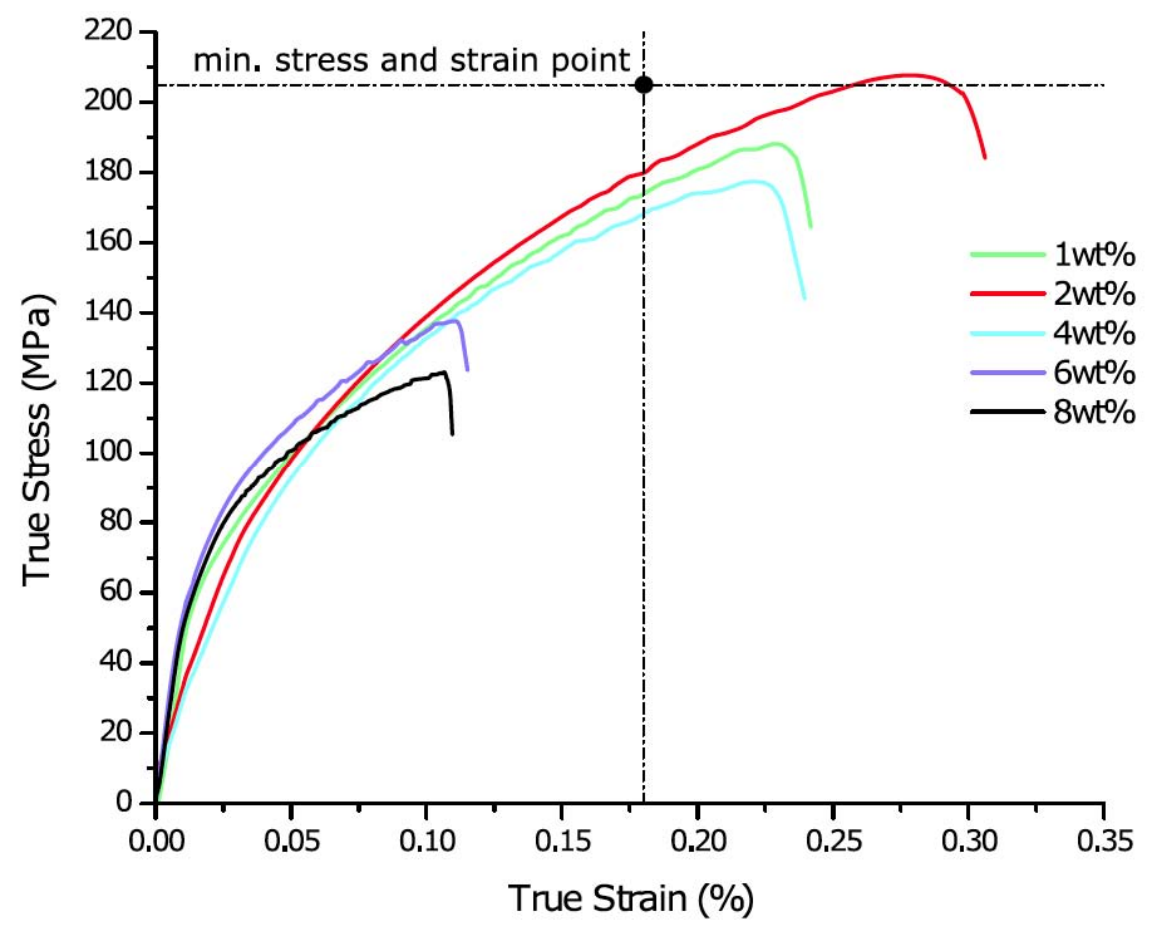

Figure 7: The effect of chromium content on the stress-strain behaviour of the composite. 
deteriorating in the mechanical properties due to inhomogeneous distribution and clustering of the reinforcing phase

- $\quad 2$ wt \% of chromium reinforced aluminium matrix composite has surpassed the minimum standard of aluminium AA6061-T4, in terms of UTS and ETF. Therefore, fabrication of composite with recycled aluminium chips through hot press forging proves to be an alternative to composite production and secondary aluminium production resources that can be further explored.

\section{ACKNOWLEDGEMENT}

The authors would like to express the deepest appreciation to the Ministry of Higher Education (MOHE), Malaysia, for funding this project through the Fundamental Research Grant Scheme (FRGS -vot numbers 1426, 1463, 1496) and Research Grant for Post Graduate (GPPS U831), UTHM. Additional supports in terms of facilities were also provided by Sustainable Manufacturing and Recycling Technology, Advanced Manufacturing and Materials Centre (SMART-AMMC), Universiti Tun Hussein Onn Malaysia (UTHM).

\section{REFERENCES}

[1] Kok M. Production and mechanical properties of Al2O3particle-reinforced 2024 aluminium alloy composites. J Mater Process Technol 2005; 161(3): 381-7. https://doi.org/10.1016/i.jmatprotec.2004.07.068

[2] Torralba JM, Costa CE, Velasco F. P / M aluminum matrix composites: an overview 2003; 133: 203-6. https://doi.org/10.1016/S0924-0136(02)00234-0

[3] Dobrza LA, Włodarczyk A, Adamiak M. The structure and properties of PM composite materials based on EN AW-2124 aluminum alloy reinforced with the $\mathrm{BN}$ or $\mathrm{Al} 2 \mathrm{O} 3$ ceramic particles 2006; 175: 186-91. https://doi.org/10.1016/j.jmatprotec.2005.04.031

Shorowordi KM, Laoui T, Haseeb ASMA, Celis JP, Froyen L. Microstructure and interface characteristics of $\mathrm{B} 4 \mathrm{C}, \mathrm{SiC}$ and Al2O3reinforced Al matrix composites: A comparative study. J Mater Process Technol 2003; 142(3): 738-43. https://doi.org/10.1016/S0924-0136(03)00815-X

Gronostajski JZ, Kaczmar JW, Marciniak H, Matuszak A. Direct recycling of aluminium chips into extruded products. J Mater Process Technol 1997; 64(1-3): 149-56. https://doi.org/10.1016/S0924-0136(96)02563-0

[6] Güley V, Ben Khalifa N, Tekkaya AE. Direct recycling of 1050 aluminum alloy scrap material mixed with 6060 aluminum alloy chips by hot extrusion. Int J Mater Form 2010; 3(SUPPL. 1): 853-6. https://doi.org/10.1007/s12289-010-0904-z

[7] Khamis SS, Lajis MA, Albert RAO. A sustainable direct recycling of aluminum chip (AA6061) in hot press forging employing Response surface methodology. Procedia CIRP [Internet] 2015; 26: 477-81.

https://doi.org/10.1016/j.procir.2014.07.023
$[8]$

Yusuf NK, Lajis MA, Daud MI, Noh MZ. Effect of Operating Temperature on Direct Recycling Aluminium Chips (AA6061) in Hot Press Forging Process. Appl Mech Mater 2013; 315: 728-32.

https://doi.org/10.4028/www.scientific.net/AMM.315.728
[9]
Ahmad A, Lajis MA, Yusuf NK, Wagiman A. Hot press forging as the direct recycling technique of aluminium- A review. ARPN J Eng Appl Sci 2016; 11(4): 2258-65.

Wan B, Chen W, Lu T, Liu F, Jiang Z. Review of solid state recycling of aluminum chips. Resour Conserv Recycl [Internet] 2017; 125(September 2016): 37-47. https://doi.org/10.1016/j.resconrec.2017.06.004

Lajis MA, Ahmad A, Yusuf NK, Azami AH, Wagiman A. Mechanical properties of recycled aluminium chip reinforced with alumina (Al2O3) particle: Mechanische Eigenschaften von mit Aluminiumoxid (Al2O3) verstärkten recycelten Aluminiumspänen. Materwiss Werksttech 2017; 48(3): 30610.

https://doi.org/10.1002/mawe.201600778

Rahimian M, Ehsani N, Parvin N, Baharvandi HR. The effect of sintering temperature and the amount of reinforcement on the properties of Al-Al2O3 composite. Mater Des [Internet] 2009; 30(8): 3333-7.

https://doi.org/10.1016/j.matdes.2008.11.027

Rahimian M, Parvin N, Ehsani N. Investigation of particle size and amount of alumina on microstructure and mechanical properties of $\mathrm{Al}$ matrix composite made by powder metallurgy. Mater Sci Eng A [Internet] 2010; 527(4-5): 10318.

https://doi.org/10.1016/j.msea.2009.09.034

B209-14 A. Standard Specification for Aluminium and Aluminium-Alloy Sheet and Plate 2014; (November).

G131-96 A. Standard Practice for Cleaning of Materials and Components by Ultrasonic Techniques 1996; 15: 1-5.

Ahmad A, Lajis MA, Yusuf NK. On the role of processing parameters in Producing recycled aluminum AA6061 based metal matrix composite (MMC-AIR) prepared using hot press forging (HPF) process. Materials (Basel) 2017; 10(9).

https://doi.org/10.3390/ma10091098

Yusuf NK, Lajis MA, Ahmad A. Multiresponse Optimization and Environmental Analysis in Direct Recycling Hot Press Forging of 2019. https://doi.org/10.3390/ma12121918

ASM International Handbook Committee. ASM Handbook: Materials Selection and Design. CRC Press; 1997. direct recycling technique of aluminium: Mechanical properties and surface integrity. Materials (Basel) 2017; 10(8). https://doi.org/10.3390/ma10080902

\section{Metallic Materials 2004;}

Ceschini L, Minak G, Morri A. Forging of the AA2618/20 vol.\% Al2O3pcomposite: Effects on microstructure and tensile properties. Compos Sci Technol [Internet] 2009; 69(11-12): 1783-9.

https://doi.org/10.1016/j.compscitech.2008.08.027

Canakci A, Varol T. Microstructure and properties of AA7075/AI-SiC composites fabricated using powder metallurgy and hot pressing. Powder Technol [Internet] 2014; 268: 72-9 https://doi.org/10.1016/j.powtec.2014.08.016

Yusuf NK, Medi AS, Lajis MA, Chan BL, Shamsudin S. Mechanical Properties of Direct Recycling Metal Matrix Composite ( MMC-AIR ) AA7075 Aircraft Aluminium Alloy 2021; 7: 89-94.

Ghorbani MR, Emamy M, Nemati N. Microstructural and mechanical characterization of $\mathrm{Al}-15 \% \mathrm{Mg} 2 \mathrm{Si}$ composite 
containing chromium. Mater Des [Internet] 2011; 32(8-9): 4262-9.

https://doi.org/10.1016/j.matdes.2011.04.020

[25] Rahimian M, Ehsani N, Parvin N, Baharvandi $\mathrm{H}$ reza. The effect of particle size, sintering temperature and sintering time on the properties of Al-Al2O3 composites, made by powder metallurgy. J Mater Process Technol 2009; 209(14): 5387-93.

https://doi.org/10.1016/j.jmatprotec.2009.04.007 